\title{
Fundamentals on the spigot capacity of dense medium cyclones
}

\author{
Mohloana K. Magwai ${ }^{\mathrm{a}}$ and Jeremy Bosman ${ }^{\mathrm{a}}$ \\ ${ }^{a}$ Department of Material Science and Metallurgical Engineering, University of Pretoria, \\ Pretoria, Gauteng 0002, South Africa
}

\section{Abstract}

The capacity of dense medium cyclones is often restricted by the solids-carrying capacity of the underflow, referred to as spigot capacity. Cyclone manufacturers normally recommend the spigot capacity for a cyclone of a particular size; however, it is not clear how these capacities are determined and whether they can be increased. In the literature, spigot capacity has previously been associated with roping flow at the underflow, although this notion has neither been clearly proven nor disproved. Furthermore, the effect of overloading the spigot on the operation of a dense medium cyclone has not been adequately studied.

In this study, test-work on a $165 \mathrm{~mm}$ diameter dense medium cyclone was performed to investigate its spigot overloading behaviour. This work established clearly that spigot capacity was reached at the onset of roping flow, and that there was a critical underflow ore concentration at which roping/spigot overloading occurred. This ore concentration was shown to be a useful tool in anticipating and avoiding spigot overloading. Spigot capacities obtained in this study were higher than those specified in the DSM handbook, indicating that dense medium cyclone could possibly be operated at higher spigot capacities. However, separation efficiencies were not monitored during this investigation.

\section{Article Outline}

1. Introduction

2. Experimental procedure

3. Results and discussion

3.1. Spigot loading

3.2. The underflow solids concentration

3.3. Slurry flow

3.4. Spigot capacity

4. Conclusions

Acknowledgements

References 


\section{Introduction}

Dense medium cyclones are used extensively in the mineral processing industry to beneficiate diamonds, coal and iron ore amongst others. The separation takes place according to the difference in densities between the minerals. Cyclones have the ability to achieve high capacities, and simultaneously obtain sharp separations and high separation efficiencies. However, this piece of equipment does have a shortcoming in that its capacity is constrained by the solids carrying capacity of the spigot. This is termed the spigot capacity. Once the spigot capacity is exceeded, the separation efficiency of the cyclone suffers and some of the sinks material report to the overflow. In applications whereby relatively large quantities of the feed material exit through the underflow, the spigot acts as a 'bottleneck' (Bosman, 2003). In order to achieve the required underflow capacity, it becomes necessary to install larger or more cyclones.

Manufacturers guidelines such as those provided by the original developers of the dense medium cyclone, Dutch State Mines (DSM) in the so-called DSM handbook (Anon.), normally specify the spigot capacity for a cyclone of a particular size. Due to the fact that the DSM guidelines "left no issue in doubt" and the dense medium cyclone performed as guaranteed when the DSM guidelines were followed (Moorhead and Schutte, 2005), the specified spigot capacities have been widely accepted. There is, however, uncertainty with regard to how these capacities were determined and whether they can be increased. Van der Walt, 1950 and Cohen and Isherwood, 1960 established that there is a maximum underflow ore carrying capacity, and they both associated it with a rise in the separation density of the cyclone. Stas (1957) identified that the cyclone was operating in an "overloaded" condition when a rope discharge was prevalent at the underflow; he did not, however, necessarily link this with the spigot capacity. He also observed that the overflow slurry density increased with increasing feed ore concentration when roping was prevalent at the spigot. Upadrashta and Venkateswarlu (1982) proposed that the "underflow discharge capacity" is exceeded when a rope discharge is encountered at the underflow, but without any evidence to support this notion. None of these authors studied the behaviour of the dense medium cyclone as the spigot got overloaded, and no clear link between roping and spigot capacity has thus far been reported.

Stas (1957) proposed a mathematical expression that could be used to predict the onset of spigot overloading of the cyclone. This expression made use of the underflow slurry density as an indicator of when roping will occur, and was based on the premise that there is a critical underflow ore concentration beyond which roping takes place. Clarkson and Wood (1993) used a similar criterion, in which they propose that spigot overloading occurs at volumetric underflow ore concentration in excess of $40 \%$.

This study aims to investigate the spigot overloading behaviour of the dense medium cyclone, and establish whether the spigot capacity is indeed reached when roping occurs (or not). Furthermore, the spigot capacity specified by DSM was compared to that obtained in this study. Lastly, ways of detecting and identifying spigot overloading within the cyclone were proposed. 
This paper does not investigate the effect of various variables such as cyclone geometry and operational variables on the spigot overloading behaviour of dense medium cyclones. In addition, changes in the separation efficiency and separation density during the overloading of the spigot were not investigated. Future work will be performed to investigate these issues. Although the authors acknowledge the relevance and importance of this kind of work to other cyclonic devices and applications, this paper will focus mainly on dense medium cyclones.

\section{Experimental procedure}

A polyurethane cyclone with an internal body diameter of $165 \mathrm{~mm}$ (Fig. 1b) was used to perform the test work. Fig. 1a shows a schematic diagram of the test rig used; in which the cyclone was installed at an inclination angle of $20^{\circ}$ from the horizontal, and the sump below it had a capacity of about $180 \mathrm{~L}$. The bypass valve was kept open for all the tests. 
a
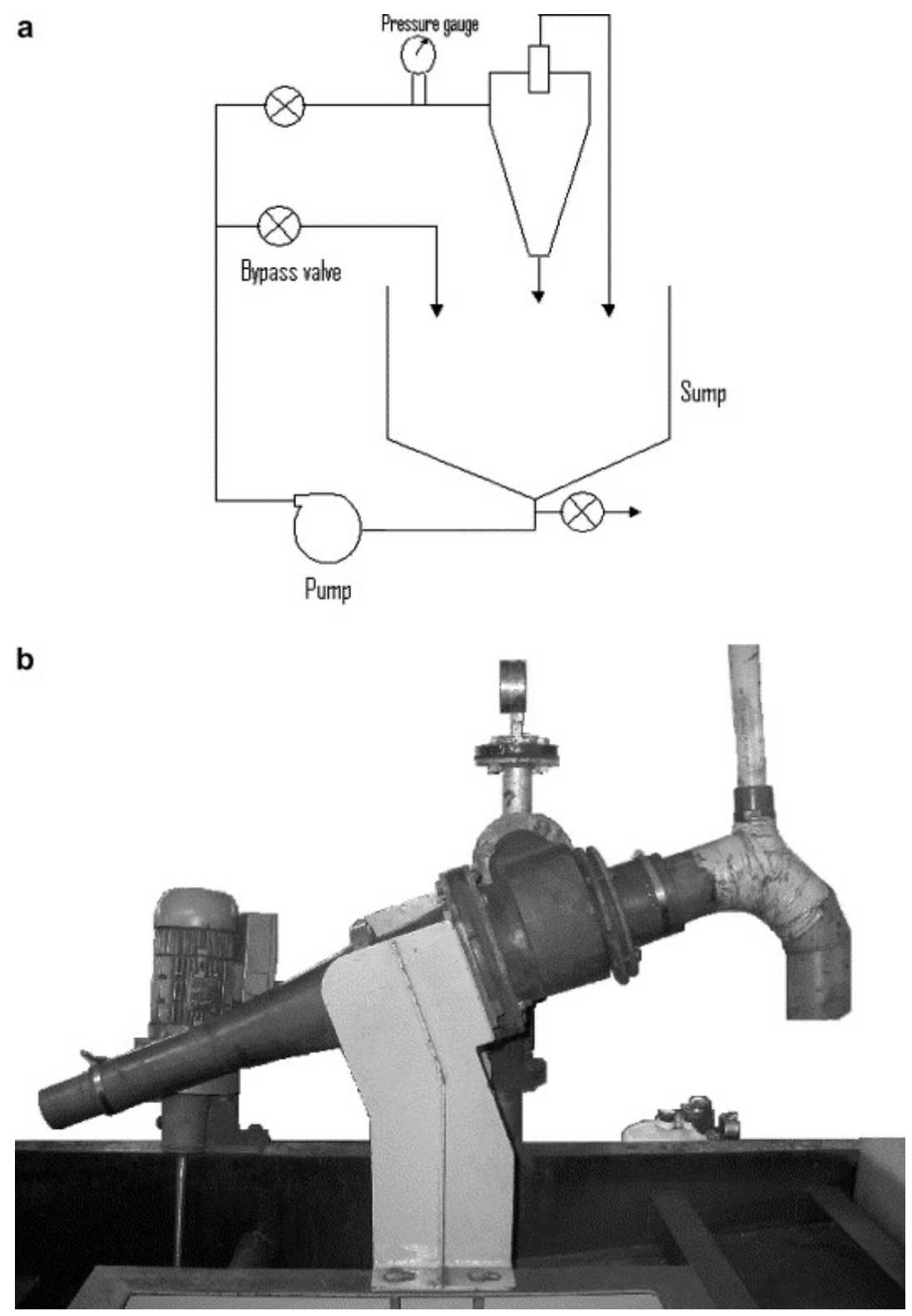

Fig. 1. (a) A schematic of the test rig and (b) polyurethane cyclone employed to perform the experiments.

An aqueous suspension of magnetite particles was used as medium and the magnetite particles were $95 \%-45 \mu \mathrm{m}$. Silica particles $(-1.8+0.8 \mathrm{~mm})$ were used as ore, so that all of the ore was concentrated to the underflow and only medium exits at the overflow. A feed pressure of $20 \mathrm{kPa}$, which is equivalent to a head of 9.5 cyclone diameters, was maintained throughout and the medium density was kept at around $1.3 \mathrm{~kg} / 1$ for all the tests. Table 1 shows the cyclone configuration. 


\section{Table 1.}

The configuration of the cyclone used to perform test-work

\begin{tabular}{|l|l|}
\hline Cyclone diameter $(\mathrm{mm})$ & 165 \\
\hline Inlet area $(\mathrm{mm} \times \mathrm{mm})$ & $70 \times 10$ \\
\hline Vortex finder diameter $(\mathrm{mm})$ & 64 \\
\hline Spigot diameter $(\mathrm{mm})$ & 45 \\
\hline Cone angle $\left(^{\circ}\right)$ & 15 \\
\hline Barrel length $(\mathrm{mm})$ & None \\
\hline
\end{tabular}

During the test-work silica particles were added into the cyclone in increments until the spigot was overloaded. Spigot overloading was easily recognizable by the change in type of discharge at the spigot, and the presence of silica particles in the overflow. Subsequent to every incremental addition of ore particles, flow-rate measurements were performed at both the overflow and underflow outlets. At least five flow-rates measurements were performed at each outlet per test. This was followed by the taking of simultaneous samples at both outlets to determine the volumetric percentage of ore and medium. Due to the large differences in particle sizes between the magnetite and silica particles, the two could easily be separated out by wet screening to determine the volumetric compositions of the slurry at each outlet.

\section{Results and discussion}

In order to elucidate on the spigot overloading behaviour of the dense medium cyclone, a number of parameters were studied during the transition to overloading. Spigot loading (in $1 / \mathrm{h}$ of both slurry and ore) and the volumetric $\%$ ore concentration in underflow were monitored during the transition. Spigot overloading is often associated with the displacement of sinks particles to the overflow, hence, the amount of silica particles exiting through the overflow were also monitored. Medium behaviour within the cyclone during spigot overloading was also investigated by monitoring the medium flow (at both the overflow and underflow) and the density differential.

\subsection{Spigot loading}

Three types of discharges were observed at the underflow depending on the ore concentration within the cyclone. At low concentrations a spray discharge was observed at the underflow, as shown in Fig. 2a, and a rope discharge was encountered at high ore concentrations (Fig. 2b). A semi-rope discharge was observed at intermediate concentrations. 

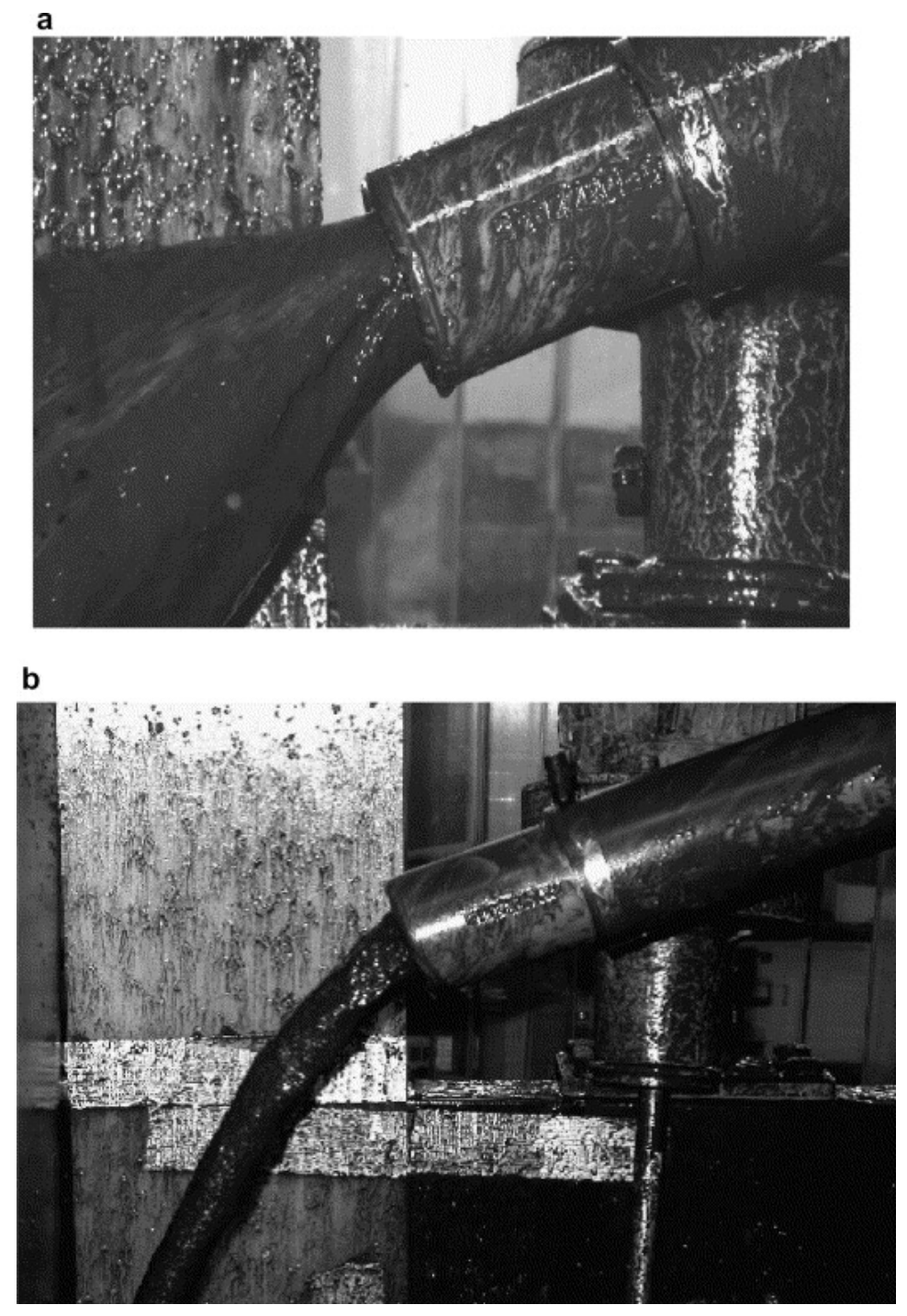

Fig. 2. (a) Spray and (b) rope discharge at the underflow.

During semi-roping, the flow at the underflow switched continuously between spray and rope discharges; being mostly spray discharge close to about $11 \%$ feed ore concentration and predominantly rope discharge at around $21 \%$ (Fig. 3). As would be expected an increase in the feed ore concentration resulted in increased spigot loading, and the relationship is linear. This linear relationship was observed when spray and semi-roping discharges prevailed at the underflow. However, as soon as the underflow changed to roping flow, further increase in the feed ore concentration did not result in more increase in spigot loading. Instead the spigot appeared to have reached its maximum ore carrying capacity. Thus, spigot capacity of the cyclone was reached at the onset of rope discharge at the underflow. 


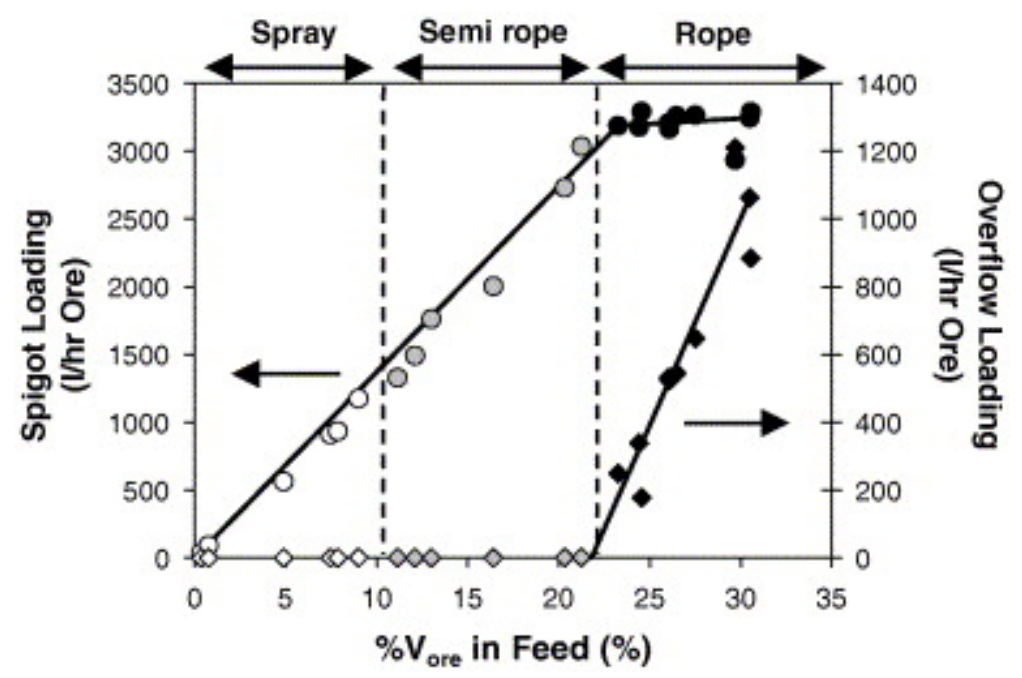

Fig. 3. Changes in the ore loading at both the overflow and underflow outlets as ore was added into the cyclone.

The onset of roping flow was also observed to be the point at which silica particles, which were supposed to exit at the underflow, were displaced to the overflow (Fig. 3). This will obviously be to the detriment of the separation efficiency and cut-density achieved in the cyclone. It is interesting to note that the displacement of ore to the overflow did not actually begin during semi-roping flow, but rather at the commencement of rope discharge. When spray and semi-rope discharges prevailed at the underflow, some silica particles of very small quantities were observed to exit at the overflow. It is thought this behaviour was due to short-circuiting of the silica particles to the overflow.

\subsection{The underflow solids concentration}

The data points obtained during semi-rope discharge were more erratic than those for spray and rope discharges (Fig. 4); this behaviour was due to the continuous change in the discharge types at the underflow between spraying and roping. The transition from a semi-rope to a rope discharge resulted in a sharp increase in the volumetric underflow ore concentration.

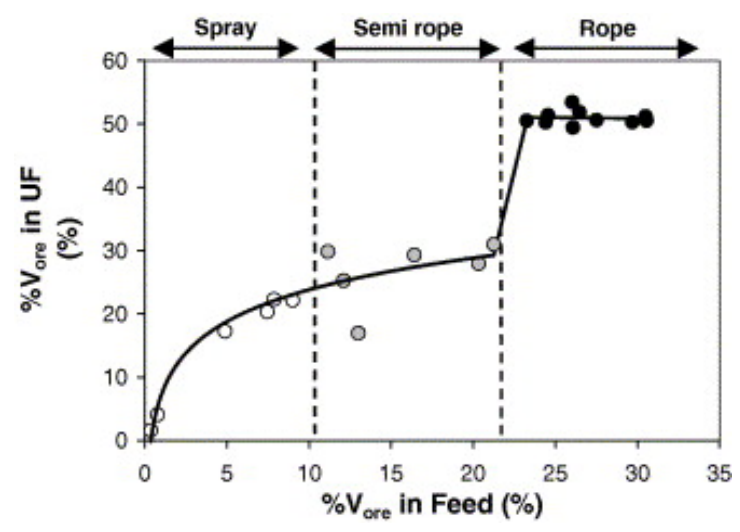


Fig. 4. The volumetric ore concentration at the underflow.

Fig. 4 shows that there was a critical underflow ore concentration beyond which the spigot became overloaded. Under overloaded conditions, the underflow ore concentration remained constant at around 50\% with further increase in the feed ore concentration. Stas (1957) too observed that when the spigot was overloaded, the underflow ore concentration remained constant with further increase in the feed ore concentration. There appears to be a small disparity between Fig. 4 and Clarkson and Wood (1993)'s proposed underflow ore concentration upper limit of $40 \%$ (to avoid spigot overloading). However, this disparity is probably due to the inclusion of a safety factor in Clarkson and Wood's underflow ore concentration upper limit. It was not possible in this study to maintain underflow ore concentrations at values between approximately $31-50 \%$; as soon as the ore concentration exceeded about $31 \%$ the air core at the underflow collapsed and roping commenced. Although there might be some differences with regard to the value of the underflow ore concentration at which spigot overloading occurs; it is clear that the onset of spigot overloading can be anticipated by monitoring the underflow ore concentration.

An argument that often arises with regard to anticipating the onset of roping is whether the feed ore concentration (or medium:ore ratio in the feed) could be used to predict the onset of roping. It is the authors' opinion that the best (and simplest) indicator of the onset of roping is the volumetric underflow ore concentration. This can best be illustrated by considering an example of two hypothetical cyclones of the same dimensions, operating under the same conditions except that cyclone A is fed with silica only, and cyclone B with coal and silica. Assume that both cyclones are operating at a medium density above that of the coal and below that of the silica. If the two cyclones are allowed to reach the roping state, and a figure similar to Fig. 4 is plotted for both cyclones, the following is expected:

- during roping the volumetric underflow ore concentration for both cyclones should be around $50 \%$, however,

- the feed concentration for cyclone $\mathrm{A}$ at the onset of roping would be less than that of cyclone $\mathrm{B}$ because of the coal present in the feed. Ideally all the coal should exit at the overflow.

Furthermore, once roping has commenced the underflow concentration remains constant with increasing feed concentration (Fig. 4). It is, therefore, clear that the feed ore concentration is not an appropriate indicator of the onset of roping.

It is not clear whether the presence of coal particles in the overflow would change the nature of the relationship between the feed and underflow concentrations as shown in Fig. 4. The presence of floats in the overflow is, however, not expected to significantly change the critical underflow ore concentration at which roping is encountered. A regression of Fig. 4 during spray and semi-rope discharges gives the following expression:

$$
\% V_{\text {ore }(\mathrm{UF})}=n \ln \left[\% V_{\text {ore }(\text { Feed }+\rho 50)}\right]+k
$$


with $n=7.223$ and $k=7.165$, and $R^{2}=0.981 . \% V_{\text {ore(UF) }}$ is the volumetric percentage of ore in the underflow during spray and semi-roping, and $\% V_{\text {ore }(\text { Feed }+\rho 50)}$ is the volumetric percentage of ore in the feed with densities above the cut density at which the cyclone is operating at. It is expected that parameters $n$ and $k$ should change with changes in the cyclone geometry and operating conditions. However, the nature of these changes has yet to be determined. Note that the two data points that appear to be outliers at semi-roping regime in Fig. 4 were not considered in obtaining the above expression.

The above expression describes how $\% V_{\text {ore(UF) }}$ increases with increasing $\% V_{\text {ore(Feed }+\rho 50) \text {, }}$ for the conditions under which these tests were performed. It does not take into account the onset of roping, thus, prior knowledge of the $\% V_{\text {ore(Feed }+\rho 50)}$ (at which the abrupt jump in $\% V_{\text {ore(UF) }}$ occurs or) at the onset of roping is required.

\subsection{Slurry flow}

The slurry flow-rate at the underflow increased in a similar manner to the ore flow-rate before roping flow commenced at the underflow (Fig. 5). During the transition to roping a drastic drop in the slurry flow-rate occurred, after which the flow-rate remained constant with further addition of ore into the cyclone. The ore flow-rate did not change abruptly during this transition (Fig. 3), thus, the abrupt drop in slurry loading at the underflow was a consequence of changes in the behaviour of medium flow (Fig. 7). This also accounts for the sudden increase in the underflow ore concentration during the transition to roping flow (Fig. 4).

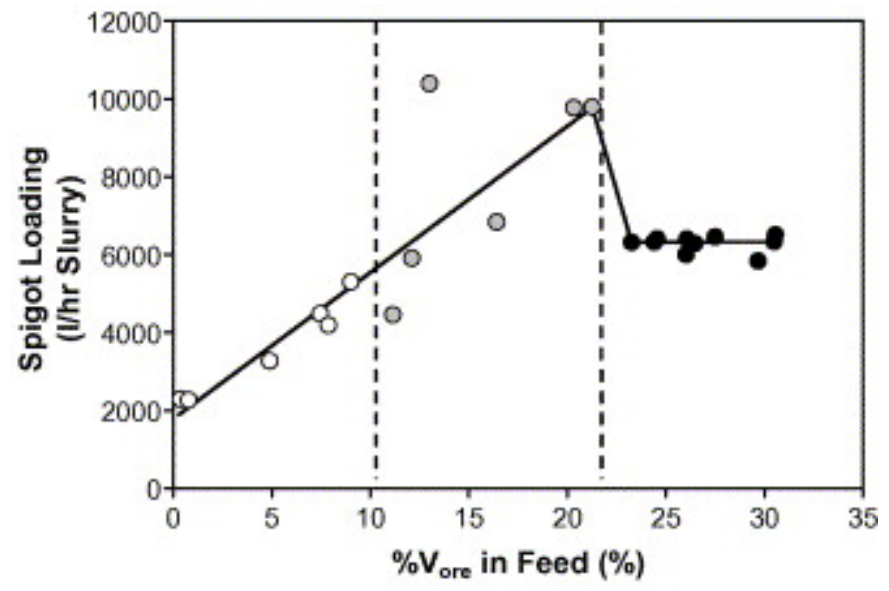

Fig. 5. Slurry loading at the underflow. 


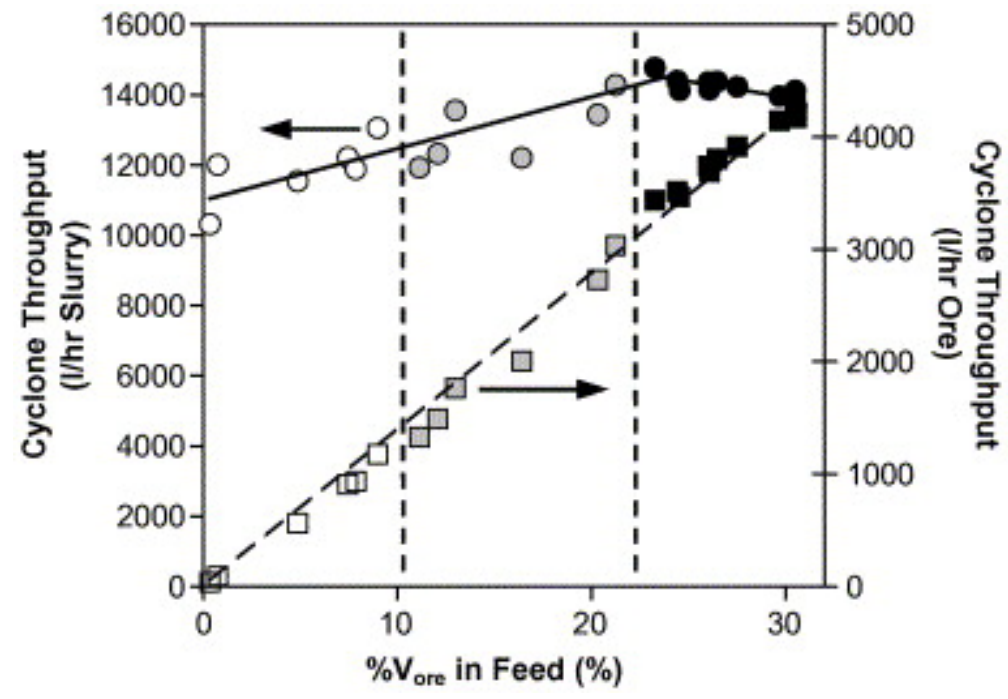

Fig. 6. Cyclone throughput (both ore and slurry) during the transition to rope discharge.

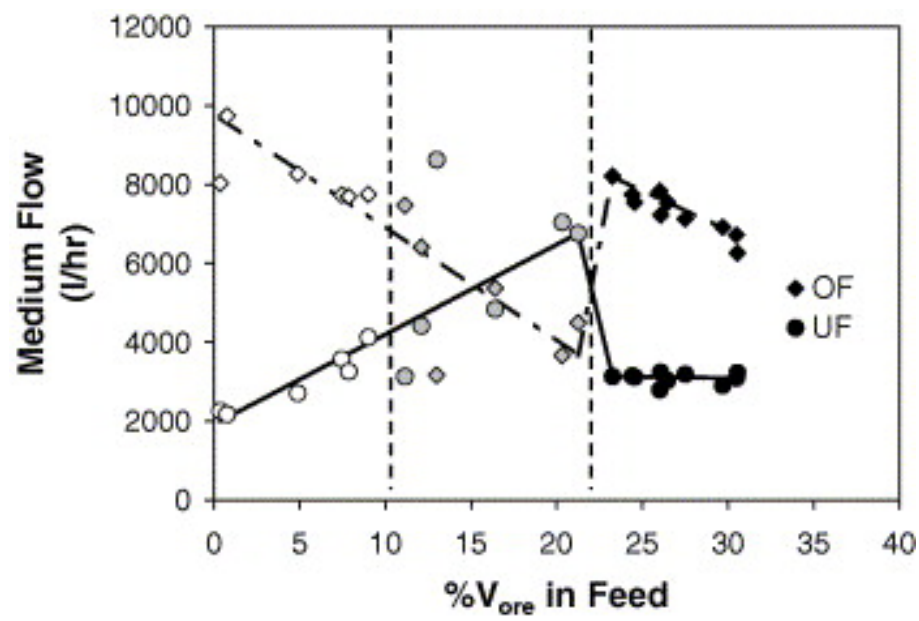

Fig. 7. Medium flow-rate at the overflow and underflow during the transition to rope discharge.

Fig. 6 shows the influence of increasing feed ore concentration on the cyclone throughput. The slurry throughput through the cyclone increased with increasing feed concentration during spray and semi-rope discharges. Once roping commenced, the throughput decreased with further increase in feed ore concentration. This decrease in the slurry throughput is actually a consequence of the decreasing overflow flow-rate during roping; the conditions at the underflow have been established to be constant once roping commences (Fig. 3, Fig. 4 and Fig. 5). The decrease in the slurry flow-rate at the overflow is reflected in the decreasing overflow medium flow-rate as shown in Fig. 7. The increase in the ore throughput with increasing feed concentration during spray and semi-rope discharges (Fig. 6) is the same as that shown in Fig. 3 (for the spigot loading). While the ore throughput increase during roping (Fig. 6) is a reflection of the increase in 
the ore flow-rate through the overflow; the ore flow-rate through the underflow remains constant with further increase in the feed concentration once roping commences (Fig. 3). During the transition to roping the medium flow-rate at the underflow dropped abruptly, and this coincided with a drastic rise in the medium flow-rate at the overflow; indicating that the collapse of the air core at the spigot resulted in a transfer of medium from the underflow to the overflow. The steady drop in medium flow-rate at the overflow during roping is a consequence of increased quantities of silica particles that have been displaced to the overflow as shown in Fig. 3.

Furthermore, there was a transfer of medium from the overflow to the underflow with increasing feed ore concentration before roping commenced (Fig. 7). This is thought to be a consequence of the interaction between the silica particles and medium, resulting in the 'dragging' of medium to the spigot.

The above-mentioned transfer of medium from the overflow to the underflow with increased addition of silica particles into the cyclone was further confirmed by the behaviour of the density differential parameter (Fig. 8).

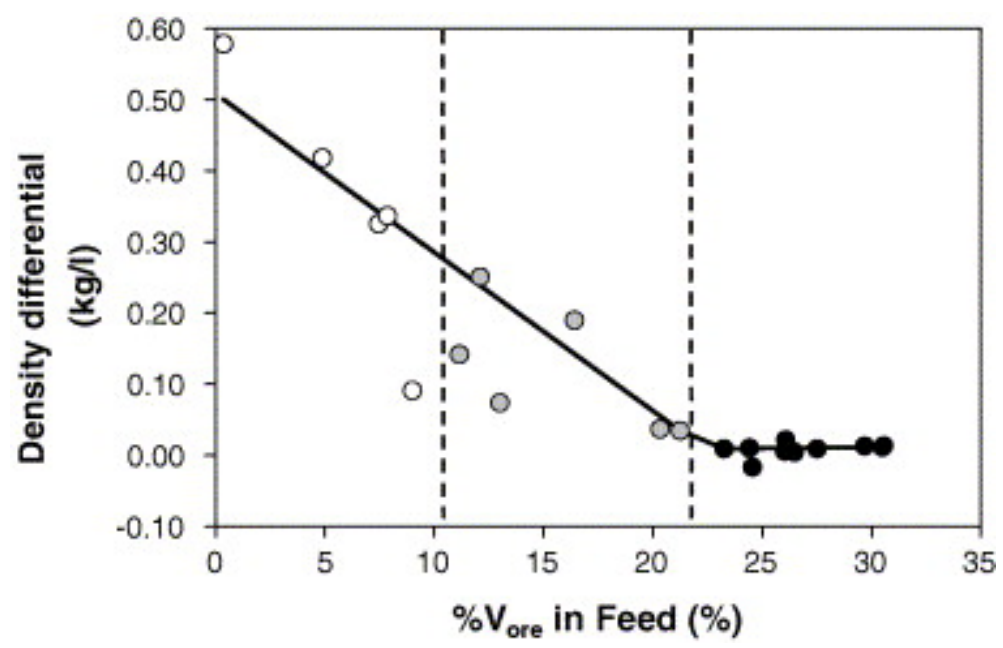

Fig. 8. Density differential across the cyclone during the overloading of the underflow.

Density differential refers to the difference between the underflow and overflow medium densities. The decrease in the differential is a consequence of the dilution of the highdensity medium at the underflow by the low-density medium from the overflow that was carried over to the spigot by the ore particles. The actual values of the density differentials shown in Fig. 8 might change in the presence of low-density ore particles or floats (that would normally exit at the overflow), due to the consequent interaction between the floats particles and medium. The trend of the curve in Fig. 8 is, however, not expected to change, thus, spigot overloading should always be associated with relatively low-density differentials. Density differential is commonly used as an indicator of the medium stability with the cyclone (Collins et al., 1983); it would therefore be expected that under viscous conditions (such as overloading of the spigot) the density differential 
should be low. Monitoring of this parameter could prove to be a useful diagnostic tool in detecting and avoiding spigot overloading in the cyclone.

\subsection{Spigot capacity}

Table 2 shows a comparison between the spigot capacity obtained in this study and that specified in the DSM handbook (Anon.). The spigot capacity from this study given in Table 2 is in fact $80 \%$ of the actual spigot capacity. Normal cyclone operation usually takes place with a spray discharge at the spigot, hence, the introduction of the safety factor. The value of $80 \%$ was chosen arbitrarily in this case; the decision on this safety factor will be based on the behaviour of the separation efficiency at around the transition point to roping. This is the subject of further work. The stability/sensitivity of the slurry flow through the spigot close to the transition to roping should also play a role in determining the above-mentioned safety factor.

Table 2.

Comparison of the spigot capacity obtained in this study with that from DSM handbook

\begin{tabular}{|l|l|}
\hline Cyclone diameter (mm) & Spigot capacity $\left(\mathbf{m}^{\mathbf{3}} \mathbf{h}\right)$ \\
\hline 165 & 2.56 \\
\hline 200 & 2.5 \\
\hline
\end{tabular}

The spigot capacity obtained in this study was slightly higher than that given in the DSM handbook, even though a larger cyclone (of $200 \mathrm{~mm}$ ) was employed in the manufacturers guidelines. Thus, depending on how the separation efficiency is affected, the cyclone could possibly be operated at higher spigot capacities than those in the manufacturer's guidelines.

\section{Conclusions}

This study has established that the onset of rope discharge at the underflow represents the point at which the spigot capacity of the dense medium cyclone was reached. The type of flow at the spigot was monitored, and related to the spigot loading (and consequently the spigot capacity). During the onset of roping some of the sinks particles, which were supposed to exit at the underflow, were displaced to the overflow, and thus increased the separation density.

A critical underflow ore concentration at which spigot overloading occurs has been observed. The quantity of the critical underflow ore concentration observed in this study was about $50 \%(\mathrm{v} / \mathrm{v})$, and it remained constant with further addition of ore into the cyclone. It has been established that the onset of spigot overloading can be predicted or anticipated by monitoring the volumetric underflow ore concentration. Roping was observed to occur when the underflow concentration exceeded about $31 \%(\mathrm{v} / \mathrm{v} \%)$; underflow concentrations between $31 \%$ and $50 \%$ could not be maintained in this study. 
Medium flow behaviour within the cyclone has been observed to govern the behaviour of various parameters of importance during the transition to roping, namely: the underflow ore concentration, slurry flow through the outlets, and the density differential. This was especially true at the onset of spigot overloading.

The density differential decreased to exceedingly low values during the transition to roping, and this parameter could possibly be useful in detecting and/or avoiding overloading of the spigot.

The spigot capacity obtained in this study was slightly higher than that specified by DSM even though a smaller diameter cyclone was used, and it appears that the specified spigot capacities (by cyclone manufacturers) could potentially be increased.

\section{References}

Anon., Anon. The Heavy Medium Cyclone Washery for Minerals and Coal. Dutch State Mines (DSM) Handbook.

Bosman, 2003 J. Bosman, Latest developments in cyclone technology, Trans. Inst. Min. Metall. (Sect. C: Min. Process Extr. Metall.) 112 (2003), pp. C10-C12.

Clarkson and Wood, 1993 C.J. Clarkson and C.J. Wood, Model of a dense medium cyclone performance, Coal Prep. 12 (1993), pp. 101-115.

Cohen and Isherwood, 1960 Cohen, E., Isherwood, R.J. 1960. Principles of dense media separation in hydrocyclones. In: International Mineral Processing Congress. Inst. Min. Met., London, pp. 573-591.

Collins et al., 1983 D.N. Collins, T. Turnbull, B.A. Wright and W. Ngan, Separation efficiency in dense medium cyclones, Trans. Inst. Min. Metall. (Sect. C: Min. Process. Extr. Metall.) 92 (1983), pp. C38-C51.

Moorhead and Schutte, 2005 Moorhead, R.G., Schutte, A., 2005. Operating guidelines for low density-density dense-medium cyclone separations. Paper presented at SA Coal Preparation Conference and Exhibition.

Stas, 1957 Stas, M., 1957. The influence of the orifices on the washing characteristics of the hydrocyclone. In: International Mineral Dressing Congress, Stockholm, pp. 161-192.

Upadrashta and Venkateswarlu, 1982 K.R. Upadrashta and D. Venkateswarlu, Study of hydrocyclone as heavy media separator, J. Powder Bulk Solids Technol. 6 (1982) (6), pp. $22-32$. 
Van der Walt, 1950 P.J. Van der Walt, Study of the operation of the cyclone washer and its application to Witbank fine coal, J. Chem. Met. Min. Soc. S. Afr. 51 (1950), pp. 19 103.

Corresponding author. Tel.: +27 12420 4549; fax: +27 123625304 . 